\title{
EFFECT OF AIR-BLOWING TIME ON THE MICROSHEAR BOND STRENGTH OF TWO UNIVERSAL ADHESIVES TO ENAMEL AND DENTIN
}

\author{
Rasha Hassan Afifi* and Mai Mamdouh Akha**
}

\begin{abstract}
Objectives: The aim of this study was to investigate the effect of air blowing time on the microshear bond strength of two universal adhesives to enamel and dentine.

Materials and methods: Thirty extracted sound human molars were used. Flat enamel and dentin surfaces were obtained by removing the buccal enamel surface of each tooth exposing the buccal enamel and dentin. The teeth were randomly divided into two equal groups $(\mathrm{N}=15)$ according to the tested adhesive system either Single Bond Universal (SBU) or all bond universal (ABU). Each group was further divided into 3 subgroups $(\mathrm{N}=5)$ according to the air blowing time i.e (5 seconds, 10 seconds, and 15 seconds). Each subgroup was further subdivided into two divisions according to the substrate either enamel or dentin. Each substrate received 2 resin composite microrods $(\mathrm{N}=10)$. After storage in distilled water $\left(37^{\circ} \mathrm{C} / 24 \mathrm{~h}\right)$, microshear bond test was performed in a universal testing machine. One-way ANOVA followed by Tukey post-hoc test was used to compare between more than two groups in non-related samples. Two-way ANOVA was used to test the interaction between different variables.
\end{abstract}

Results: There was a statistically significant difference between $(15 \mathrm{sec}),(10 \mathrm{sec})$ and $(5 \mathrm{sec})$ groups for (SBU) and (ABU) in enamel $(\mathrm{p} \leq 0.001)$. There was also statistically significant difference between $(15 \mathrm{sec}),(10 \mathrm{sec})$ and $(5 \mathrm{sec})$ groups for $(\mathrm{SBU})$ and $(\mathrm{ABU})$ in dentin $(\mathrm{p}<0.001)$.

Conclusions: Air blowing time of 15 seconds in enamel has a positive effect on microshear bond strength of universal adhesives. Air blowing time effect in dentin was material dependent.

KEYWORDS: Air blowing time, microshear, enamel, dentin, universal adhesives.

\footnotetext{
* Lecturer of Conservative Dentistry, Faculty of Dentistry, Future University in Egypt.

**Lecturer of Conservative Dentistry, Faculty of Dentistry, Cairo University Egypt.
} 


\section{INTRODUCTION}

Adhesive technology is continuously developing by several innovations of commercial adhesive formulations. The main challenge for dental adhesives, to this day, is the need for an effective bond to dental substrates of different nature. Whereas bonding to enamel is reliable and durable, it is more difficult to achieve in the dentin due to its wet tubular ultrastructure and organic composition. ${ }^{1}$ Currently, as a new branch of one-step self-etching system, the so-called 'Universal System' or 'Multipurpose System' has become commercially available and regains attention from dental clinicians as 'the eighth generation' system. Many of these systems have a common factor that they are prone to select 10 -MDP as their functional monomer, but differ in application procedures, such as: coating manner, waiting time and air-blowing pressure. ${ }^{2}$

Air-drying after application of the adhesive is considered a critical step in the bonding procedure. Within that step, many factors can affect the bond strength, including air-blowing time, air pressure, and air temperature. According to the conventional 3-step etch \&rinse adhesive systems, air-blowing step is necessary to evaporate the solvent from the primer and to obtain a uniform, thin bonding layer. On the other side, since all components were incorporated into a single bottle in one-step selfetching adhesives, it might be hard to evaporate the solvent from the complex mixture in bonding agent. ${ }^{3,4}$

In addition, variations in air drying time may occur in clinical application because of pooling of the material, tooth position in the mouth, dentin sensitivity to air blast in vital teeth and various air pressures from different air-syringes. Furthermore, for obtaining appropriate adhesive thickness for adequate bond strength in clinical applications, clinicians might prefer to over-dry instead of using the general method of gently dry the adhesive. ${ }^{5}$ Based on these controversies, the aim of this study was to evaluate the influence of different air- blowing durations on microshear bond strength of two current universal adhesive systems to enamel and dentin.

\section{MATERIALS AND METHODS}

Two commercially available universal adhesive systems were used in this study. Table 1 shows the chemical composition, specification and the respective manufacturer's instructions for application of the two adhesives.

\section{Teeth Preparation}

Thirty extracted caries-free human molars were used in this study. Immediately after extraction, the teeth were thoroughly washed, scrubbed, and scaled to remove blood, mucous, and shreds of periodontal ligament. The teeth were stored at $4{ }^{\circ} \mathrm{C}$ in sodium azide and used within 3 months after extraction. Flat enamel and dentin surfaces were obtained by removing the buccal enamel surface of each tooth in a gypsum model trimmer with water coolant, exposing dentine and exposing the buccal enamel. After that, the teeth surfaces were ground with 600-grit $\mathrm{SiC}$ paper for $60 \mathrm{~s}$ under continuous water-cooling to produce a standardized smear layer prior to bonding. The teeth were randomly divided into two equal groups $(\mathrm{N}=15)$ according to the tested adhesive system either Single Bond Universal (SBU) or All Bond Universal (ABU). Each group was further divided into 3subgroups $(\mathrm{N}=$ 5 ) according to the air blowing time i.e (5 seconds, 10 seconds, and15seconds). Each subgroup was further subdivided into two divisions according to the substrate either enamel or dentin. Each substrate received 2 resin composite microrods ( 2 on enamel and 2 on dentin, $\mathrm{N}=10$ ).

The adhesive procedures in the present study, except for the air-blowing duration, followed the respective manufacturer's instructions. The bonded surfaces were then air-blown for either $5 \mathrm{~s}, 10 \mathrm{~s}$, or $15 \mathrm{~s}$, respectively, before light-curing. The maximum air-blowing pressure was adjusted to be $0.25 \mathrm{MPa}$, and the air syringe head was positioned vertically to 
the tooth surface at a distance of $15 \mathrm{~mm}$. All systems selected in the present study were applied only as one-step self-etch materials. The same operator performed all steps.

\section{Preparation of composite cylinders:}

Two cylindrical composite buildups (Tetric Evoceram Bulk Fill) were created on the surfaces of each substrate $(\mathrm{N}=10)$ in each group using Tygon tube with an internal diameter of $0.75 \mathrm{~mm}$ and 1 $\mathrm{mm}$ length (Tygon, Norton Performance Plastic Co, Cleveland, OH, USA) under pressure with Teflon coated applicator(Composite placement instrument, 636,3M ESPE dental products, USA) and bulk-cured for $20 \mathrm{~s}$ using a light -emitting diode (LED) lightcuring unit (EliparFree Light 3, St. Paul, 3M ESPE, $\mathrm{MN}$, USA) at $1200 \mathrm{~mW} / \mathrm{cm} 2$ output. The output energy of the LED-curing device was measured periodically with a radiometer (Demetron/Kerr, Danbury, CT, USA). The failed samples before the test were replaced with new samples.

\section{Microshear bond strength test}

After storage in distilled water $\left(37^{\circ} \mathrm{C} / 24 \mathrm{~h}\right)$, the tygon tubes were removed using a scalpel, and the specimens were subjected to a universal testing machine (Instron, Model 4444, Instron Corporation, Canton, MA, USA). A $0.25 \mathrm{~mm}$ thick wire loop was placed around the composite cylinders contacting semi-circularly. Microshear bond test was performed at a crosshead speed of $0.5 \mathrm{~mm} / \mathrm{min}$. The microshear forces were recorded in Newtons $(\mathrm{N})$ and calculated as megapascals (MPa) by dividing to the bonding area $\left(\mathrm{mm}^{2}\right)$.

\section{Statistical analysis}

Data were explored for normality using Kolmogorov-Smirnov and Shapiro-Wilk tests, data showed parametric (normal) distribution. Independent sample t-test was used to compare between two groups in non-related samples. Oneway ANOVA followed by Tukey post-hoc test was used to compare between more than two groups in non-related samples. Two-way ANOVA was used to test the interaction between different variables. The significance level was set at $\mathrm{P} \leq 0.05$. Statistical analysis was performed with IBM ${ }^{\circ}$ SPSS ${ }^{2}$ (IBM Corp. Released 2015, Statistics Version 20 for Windows. Armonk, NY: IBM Corp.)

TABLE (1): Chemical composition, specification, and manufacturer's instructions for application of the universal systems adhesive systems used in the present study.

\begin{tabular}{|c|c|c|}
\hline Materials \& lot no. & Chemical formulation \& pH & Manufactures' instruction \\
\hline $\begin{array}{l}\text { All Bond Universal } \\
\text { (ABU) } \\
\text { Lot no. } 1300008729 \\
\text { (Bisco, Inc.) }\end{array}$ & $\begin{array}{l}\text { 10-MDP, Bis-GMA, HEMA, ethanol, water, } \\
\text { initiators. } \\
\mathrm{pH}=3.2\end{array}$ & $\begin{array}{l}\text { 1. Dispense } 1-2 \text { drops of bond into a clean well. } \\
\text { 2. Apply two separate coats of bond, scrubbing } \\
\text { the preparation with a micro-brush for } 10-15 \mathrm{~s} \\
\text { per coat. Do not light cure between coats. } \\
\text { 3. Evaporate excess solvent by thoroughly air- } \\
\text { drying with an air syringe for at least } 10 \mathrm{~s} \text {, there } \\
\text { should be no visible movement of the adhesive. } \\
\text { 4. Light cure for } 10 \mathrm{~s} \text {. }\end{array}$ \\
\hline $\begin{array}{l}\text { Single bond Universal } \\
\text { Lot no. } 572054 \quad(3 \mathrm{M} \\
\text { ESPE) }\end{array}$ & $\begin{array}{l}\text { 10-MDP, HEMA, ethanol, water, } \\
\text { dimethacrylate resins, methacrylate-modified } \\
\text { polyalkenoic acid copolymer, polyacrylic } \\
\text { acid copolymer, silane, fillers, initiators. } \\
\text { pH }=2.7\end{array}$ & $\begin{array}{l}\text { 1. Apply the adhesive to the prepared tooth and } \\
\text { rub it in for } 20 \mathrm{~s} \text {. } \\
\text { 2. Gently air dry the adhesive for approximately } \\
5 \mathrm{~s} \text { to evaporate the solvent. } \\
\text { 3. Light cure for } 10 \mathrm{~s} \text {. }\end{array}$ \\
\hline
\end{tabular}




\section{RESULTS}

Data in table (2) shows Two-way ANOVA analysis for the interaction of different variables in enamel. The results showed that, different materials had a statistically significant effect at P-value $<0.001$. Also, time had a statistically significant effect at $\mathrm{P}$-value $=0.001$ and. The interaction between the two variables also had a statistically significant effect at $\mathrm{P}$-value $<0.001$.

The microshear bond strength mean values of the two adhesives with different air blowing time in enamel were presented in table (3). It was revealed that, for $(A B U)$, There was a statistically significant difference between $(15 \mathrm{sec}),(10 \mathrm{sec})$ and $(5 \mathrm{sec})$ groups where $(p=0.013)$. No statistically significant difference was found between $(10 \mathrm{sec})$ and $(5 \mathrm{sec})$ groups where $(p=0.899)$. The highest mean value was found in $(15 \mathrm{sec})$, while the lowest mean value was found in $(10 \mathrm{sec})$. For (SBU), there was also statistically significant difference between $(15 \mathrm{sec})$, $(10 \mathrm{sec})$ and $(5 \mathrm{sec})$ groups where $(p<0.001)$. The highest mean value was found in $(15 \mathrm{sec})$, while the lowest mean value was found in $(5 \mathrm{sec})$.

Regarding the effect of the material, there was a statistically significant difference between (ABU) and (SBU) groups at 15, 10, and 5 seconds air blowing in enamel where ( $\mathrm{p}=0.001),(p<0.009)$, and $(p=0.002)$ respectively. The highest mean value was found in (SBU) group, while the lowest mean value was found in (ABU) group.

Data in table (4) shows Two-way ANOVA analysis for the interaction of different variables in dentin. It was revealed that, different materials had a statistically significant effect at P-value 0.007. Also, time had a statistically significant effect at $\mathrm{P}$-value $<0.001$. The interaction between the two variables also had a statistically significant effect at P-value $<0.001$.

The microshear bond strength mean values of the two adhesives with different air blowing time in dentin were presented in table (5). It was revealed that, for $\mathrm{ABU}$, there was a statistically significant difference between $(15 \mathrm{sec}),(10 \mathrm{sec})$ and $(5 \mathrm{sec})$ groups where $(\mathrm{p}<0.001)$. The highest mean value was found in $(15 \mathrm{sec})$, while the lowest mean value was found in $(10 \mathrm{sec})$. For SBU: There was also a statistically significant difference between $(15 \mathrm{sec})$, $(10 \mathrm{sec})$ and $(5 \mathrm{sec})$ groups where $(p<0.001)$. The highest mean value was found in $(5 \mathrm{sec})$, while the lowest mean value was found in $(10 \mathrm{sec})$.

Regarding the effect of the material, there was no statistically significant difference in microshear bond strength between ABU and SBU groups at 15 seconds air blowing in dentin where $(p=0.089)$.

TABLE (2): Results of Two-way ANOVA for the effect of different variables on Micro-shear bond strength in enamel.

\begin{tabular}{|l|c|c|c|c|c|}
\hline \multicolumn{1}{|c|}{ Source } & Type III Sum of Squares & df & Mean Square & F & Sig. \\
\hline Corrected Model & 72.973 & 5 & 14.595 & 35.959 & .000 \\
\hline Intercept & 1541.445 & 1 & 1541.445 & 3797.909 & .000 \\
\hline Materials & 53.282 & 1 & 53.282 & 131.281 & .000 \\
\hline Time & 9.035 & 2 & 4.517 & 11.130 & .001 \\
\hline Materials*Time & 10.656 & 2 & 5.328 & 13.127 & .000 \\
\hline Error & 7.306 & 18 & .406 & & \\
\hline Total & 1621.723 & 24 & & & \\
\hline Corrected Total & 80.278 & 23 & & & \\
\hline
\end{tabular}

df: degrees of freedom $=(n-1), *$ Significant at $P \leq 0.05$. 
Although, the highest mean value was found in ABU group, while the lowest mean value was found in SBU group. There was also no statistically significant difference between $\mathrm{ABU}$ and $\mathrm{SBU}$ groups at 10 seconds where $(p=0.251)$. The highest mean value was found in SBU group, while the lowest mean vale was found in ABU group. There was a statistically significant difference between $\mathrm{ABU}$ and SBU groups at 5 seconds air blowing in dentin where $(p=0.001)$. The highest mean value was found in SBU group, while the lowest mean value was found in ABU group.

TABLE (3): The mean, standard deviation (SD) values of Micro-shear of different groups in enamel.

\begin{tabular}{|c|c|c|c|c|c|}
\hline \multirow{2}{*}{ Variables } & \multicolumn{5}{|c|}{ Micro-shear (Enamel) } \\
\cline { 2 - 6 } & \multicolumn{2}{|c|}{ All Bond Universal (ABU) } & \multicolumn{2}{|c|}{ Single Bond Universal (SBU) } & \multirow{2}{*}{ p-value } \\
\cline { 2 - 6 } & Mean & SD & Mean & SD & $<0.001^{*}$ \\
\hline $15 \mathrm{sec}$ & 7.74 & 0.86 & 10.64 & 0.44 & 0.41 \\
\hline $10 \mathrm{sec}$ & 5.80 & 0.77 & 8.55 & 0.52 & $0.002^{*}$ \\
\hline $5 \mathrm{sec}$ & 6.04 & 0.69 & & $<0.001^{*}$ & \\
\hline
\end{tabular}

*; significant $(p<0.05) \quad n s ;$ non-significant $(p>0.05)$

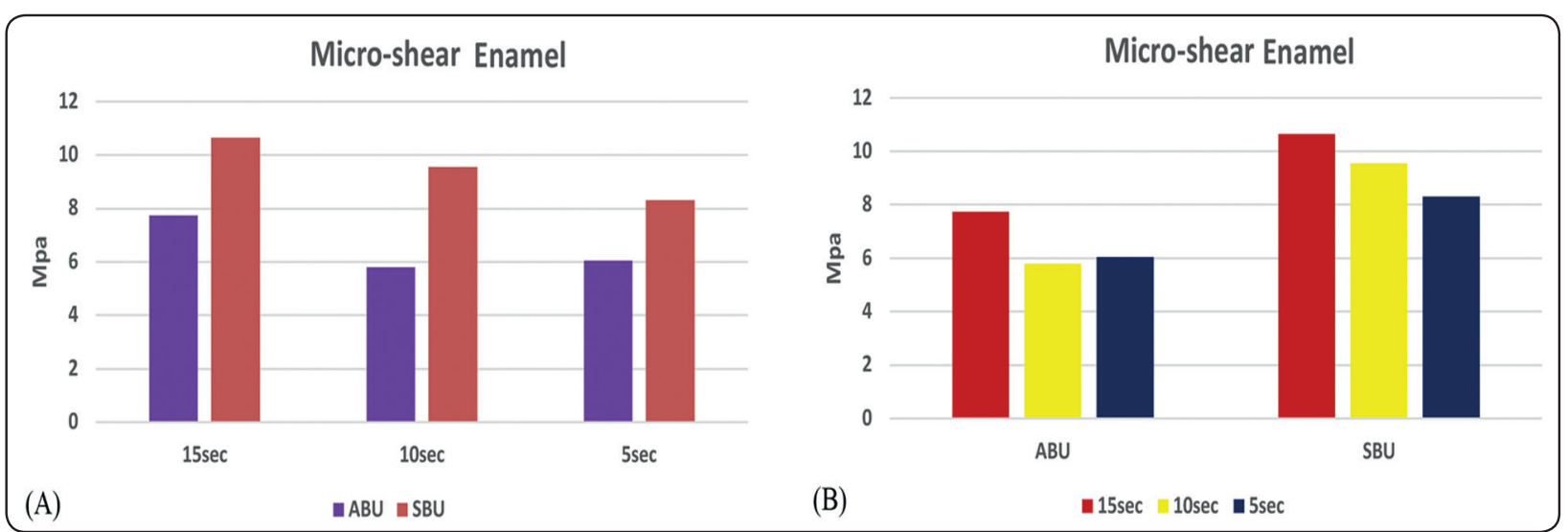

Fig. (1): Bar chart representing Micro-shear for different groups in enamel.

TABLE (4): Results of Two-way ANOVA for the effect of different variables on Micro-shear bond strength in dentin.

\begin{tabular}{|l|c|c|c|c|c|}
\hline \multicolumn{1}{|c|}{ Source } & Type III Sum of Squares & df & Mean Square & F & Sig. \\
\hline Corrected Model & 74.518 & 5 & 14.904 & 33.792 & .000 \\
\hline Intercept & 1079.505 & 1 & 1079.505 & 2447.657 & .000 \\
\hline Groups & 4.100 & 1 & 4.100 & 9.297 & .007 \\
\hline Time & 56.593 & 2 & 28.297 & 64.159 & .000 \\
\hline Material *Time & 13.824 & 2 & 6.912 & 15.673 & .000 \\
\hline Error & 7.939 & 18 & .441 & & \\
\hline Total & 1161.961 & 24 & & & \\
\hline Corrected Total & 82.456 & 23 & & & \\
\hline
\end{tabular}


TABLE (5): The mean, standard deviation (SD) values of Micro-shear of different groups in dentin.

\begin{tabular}{|c|c|c|c|c|c|}
\hline \multirow{3}{*}{ Variables } & \multicolumn{5}{|c|}{ Micro-shear (Dentin) } \\
\hline & \multicolumn{2}{|c|}{ All Bond Universal } & \multicolumn{2}{|c|}{ Single Bond Universal } & \multirow{2}{*}{ p-value } \\
\hline & Mean & SD & Mean & SD & \\
\hline $15 \mathrm{sec}$ & 8.34 & 0.70 & 7.42 & 0.57 & $0.089 \mathrm{~ns}$ \\
\hline 10sec & 4.23 & 0.43 & 4.85 & 0.87 & $0.251 \mathrm{~ns}$ \\
\hline $5 \mathrm{sec}$ & 6.31 & 0.90 & 9.09 & 0.29 & $0.001 *$ \\
\hline p-value & \multicolumn{2}{|c|}{$<0.001 *$} & \multicolumn{2}{|c|}{$<0.001 *$} & \\
\hline
\end{tabular}

*; significant $(p<0.05) \quad n s ;$ non-significant $(p>0.05)$

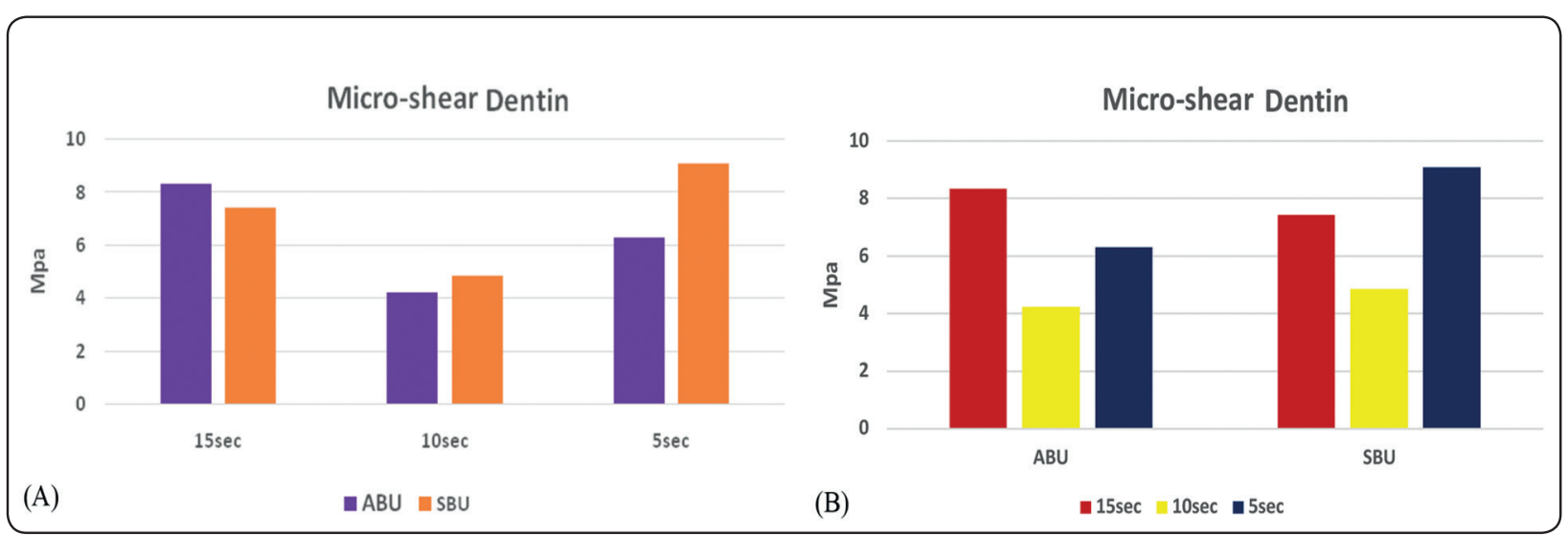

Fig. (2): Bar chart representing Micro-shear for different groups in dentin.

\section{DISCUSSION}

The present study was done to evaluate the microshear bond strength of the newly introduced multimode adhesive system: Single Bond Universal $^{\mathrm{TM}}$ and All bond universal to enamel and dentine after different air blowing times. These adhesives are among the most frequently used universal adhesives available in the market. Thus, they were tested in our study.

Of the various methods have been chosen by authors to evaluate the bond between the resin and enamel and dentin, such as microleakage at the interface, fracture toughness, tensile bond strength and shear bond strength, ${ }^{6}$ shear stress is considered to be a more representative of the clinical situation in comparison to the tensile stress. ${ }^{7,8}$ However, the conventional or macro- shear bond strength test with a bonding surface area larger than $3 \mathrm{~mm} 2$, causes non-uniform stress distribution related to internal defects due to a larger area which increases the amount of stress. On the other hand, the microshear bond strength test investigates small bonding surface areas, and a higher number of samples can be obtained from one tooth. The samples do not need sectioning, and this method is less technical sensitivity than the microtensile bond strength test. ${ }^{9}{ }^{10}$ Some previous studies have also discussed no difference or even superiority of this test over the microtensile test. ${ }^{9}$ Thus, the microshear bond strength test was carried out in this study.

In the present study, the results showed that air blowing time had a statistically significant effect on 
immediate microshear bond strength of universal adhesives to enamel and dentin and the effect was material dependent. The material had a statistically significant effect on microshear bond strength. The two-way ANOVA analysis revealed that the interaction between the material and air-blowing duration was also significant on microshear bond strength.

The results also showed that, increasing the air blowing duration improves the bond strength of both adhesives to enamel. This may be due to possible reduction of film thickness produced by increasing the air blowing time (15 seconds). Film thickness of adhesive resins is affected by subsequent airblowing. It is possible that gentle air-blowing produces thick adhesive resin layers including the dissolved smear layer. Due to presence of the smear layer, physical and mechanical properties of the photopolymerized adhesive layer may be adversely affected. Thick adhesive layer adversely affects bond strength, increases crack propagation, elevates the thermal co-efficient of expansion mismatch with the tooth and decreases the load bearing and wear component of the restoration. ${ }^{11}$ air-blowing also affects the thickness of the adhesive layer and the degree of polymerization. ${ }^{12}$ Conversely an adhesive layer should be thick enough to polymerize in the deeper reaches of the hybrid zone to permit optimal adhesion while retaining an uncured layer on the surface to bond to the composite. ${ }^{11}$

(Zheng et al. 10) suggested that the effect of the thickness of the adhesive layer on bond strength is material dependent. In their study, the increase in bond strengths of Clearfil Liner Bond $2 \mathrm{~V}$ was directly proportional to the thickness of the bonding layer and the bond strengths of Single Bond decreased significantly with increase adhesive resin thickness. They emphasized that care should be taken to avoid excess adhesive resin at line angle in cavities bonded with single bottle system that contain water and ethanol. ${ }^{13}$
The results showed that, in enamel SBU showed better bond strength than $\mathrm{ABU}$ regardless the air blowing time $(5,10$, or 15 seconds). This may be related to the lower PH of SBU compared to ABU. It is well known that enamel is a highly mineralized substrate constituted of almost 100 wt $\%$ of hydroxyapatite crystals. ${ }^{14}$ Enamel is rich in minerals thus it will give better bond strength with the adhesive that has more acidic $\mathrm{PH}$ which will properly demineralize the enamel surface.

Several studies reported that residual solvent can interfere with the polymerization of adhesives..$^{15,16}$ Therefore, increasing air-blowing time in dentin could facilitate solvent evaporation and improve bond strength. However, the effects of air-blowing time on the bond strength were different among the two universal adhesives (interaction between adhesive VS air-blowing time was $(F=15.673$, $p=0.000)$.

The results revealed that, for $\mathrm{ABU}$, there was a statistically significant difference between $(15 \mathrm{sec})$, $(10 \mathrm{sec})$ and $(5 \mathrm{sec})$ groups where $(\mathrm{p}<0.001)$. The highest mean value was found in $(15 \mathrm{sec})$. For SBU, there was also a statistically significant difference between $(15 \mathrm{sec}),(10 \mathrm{sec})$ and $(5 \mathrm{sec})$ groups where $(p<0.001)$. The highest mean value was found in $(5 \mathrm{sec})$. Extended air blowing time was expected to improve solvent evaporation with ethanol-based adhesives such as the two adhesives used in our study. Since ethanol and water can form hydrogen bond with each other and with the monomer. Therefore, it is more difficult to remove water form ethanol-based adhesives compared to those of acetone-based adhesives. ${ }^{17}$ Based on that, both adhesives should give better results with 15 seconds air blowing. However, the difference in bond strength noticed between the two adhesives in this study might be explained by their different composition. This is probably related to the various concentration or purity of 10-MDP incorporated in different systems ${ }^{18}$ and thus yielded different 
bonding performances ${ }^{19}$. One-step self-etching systems are very complex chemical productions, even though most adhesive systems contain the same components, they may differ significantly. ${ }^{20}$ This result was also in accordance with manufacturer instructions which recommend air blowing for at least 10 seconds for ABU. However, there are few researches on the performance of different universal adhesives under different air blowing times and further investigations needed.

The results showed that, with 15 - and 10-seconds air blowing in dentin there was no statistically significant difference between SBU and ABU. However, with 5 seconds of air blowing SBU showed statistically significantly higher bond strength mean values than $\mathrm{ABU}$. This might be related to the effect of Vitrebond copolymer which is incorporated in SBU. A previous study reported that the presence of Vitrebond copolymer improved the bond strength of Adper single bond plus, the predecessor of SBU. ${ }^{21}$ Therefore, the presence of Vitrebond copolymer in SBU might have also contributed to the relative microshear bond strength of SBU in the same manner. The Vitrebond copolymers also provides a satisfactory bonding to dentin under moist and dry conditions as claimed by the manufacturer. This may explain the good bond strength even if we decreased the air blowing time. In addition, SBU is recommended to be actively applied for $20 \mathrm{~s}$. Active application of SBU was reported to improve resindentin bond..$^{22}$ Moreover, the $5 \mathrm{~s}$ longer application time compared to the ABU could have enhanced the interaction between the adhesive and the tooth substrates, thus resulting in the stronger bond strength. ${ }^{3}$

\section{CONCLUSION}

Within the limitations of this in-vitro study, it could be concluded that:

1. Air blowing time of 15 seconds in enamel has relatively a positive effect on microshear bond strength of universal adhesives.
2. SBU showed better microshear bond strength mean values in enamel compared to ABU.

3. Air blowing time affects the microshear bond strength in dentin, but the effect seems to be material dependent and further investigations need to be done on the effect of air blowing time of universal adhesives.

Declaration of funding: This research did not receive any specific grant from funding agencies in the public, commercial, or not-for-profit sectors.

Conflict of interest: The Authors declare that there is no conflict of interest.

\section{REFERENCES}

1. Goud K M., Arun J., P Nishanth P., Deepak BS., Nandini TN: Comparative Evaluation of Shear Bond Strength of Three Dental Adhesives under Dry and Wet Bonding Conditions: An In Vitro Study. Journal of International Oral Health .2016; 8(2):267-271.

2. Fu J., Saikaew P., Kawano S., Carvalho RM., Hannig M., Sano H., Denis Selimovic D.: Effect of air-blowing duration on the bond strength of current one-step adhesives to dentin. Dental materials. 2017; 33:895-903.

3. Saikaew P., Fu J., Almas A., Carvalho RM., Sano H.: Effect of air-blowing time and long-term storage on bond strength of universal adhesives to dentin. Clinical Oral Investigations. 2019; 23:2629-2635.

4. Inoue S., Vargas MA., Abe Y., Yoshida Y., Lambrechts P., Vanherle G., Sano H., van Meerbeek B. Microtensile bond strength of eleven contemporary adhesives to dentin. J Adhes Dent. 2001; 3:237-245.

5. Nagas E., Cekic-Nagas I., Ergun G., Vallittu PK., Lassila LV.: Does the Period of Air-Drying Affect Dentin Bond Strength of Different Adhesive Systems? British Journal of Medicine \& Medical Research.2014; 4(27): 4523-4532.

6. Poggio C., Scribante A., Della Zoppa F., Colombo M., Beltrami R., Chiesa M.: Shear bond strength of one-step self-etch adhesives to enamel: Effect of acid pretreatment. Dent Traumatol. 2014;30(1):43-8.

7. Van Meerbeek B., De Munck J., Yoshida Y., Inoue S., Vargas M., Vijay P.: Buonocore memorial lecture. 
Adhesion to enamel and dentin: Current status and future challenges. Oper Dent 2003;28(3):215-35.

8. Mallikarjun K. , Arun J., Nishanth P., Deepak B S ., Nandini5 T N.: Comparative Evaluation of Shear Bond Strength of Three Dental Adhesives under Dry and Wet Bonding Conditions: An In Vitro Study. Journal of International Oral Health. 2016; 8(2):267-271.

9. Van Meerbeek B., Peumans M., Poitevin A., Mine A., Van Ende A., Neves A.: Relationship between bond-strength tests and clinical outcomes. Dent Mater. 2010;26(2):10021.

10. Beloica M., Goracci C., Carvalho CA., Radovic I., Margvelashvili M., Vulicevic ZR.: Microtensile vs microshear bond strength of all-in-one adhesives to unground enamel. J Adhes Dent. 2010 Dec;12(6):427-33.

11. Grossman ES, and Setzer S: Bonding agents: adhesive layer thickness and retention to cavity surfaces with time. SAD J. 2001; 56: 266-272.

12. Takai T., Hosaka K., Kambara K., Thitthaweerat S., Matsui N., Takahashi M., Kishikawa R., Nakajima M., Otsuki M., Foxton Rm., Tagami J.: Effect of air-drying dentin surfaces on dentin bond strength of a solvent-free one-step adhesive. Dental Materials Journal. 2012; 31(4): 558-563.

13. Zheng L., Pereira PNR., Nakajima M., Sano H., Tagami J.: Relationship between adhesive thickness and microtensile bond strength. Oper Dent 26(1):97-104, 2001.

14. Isolan C., Valente L., Münchow E., Basso G, Pimentel A., Schwantz J., Andreza V., Da Silva A., Rafael R Moraes R.: Bond strength of a universal bonding agent and other contemporary dental adhesives applied on enamel, dentin, composite, and porcelain. Applied Adhesion Science. 2014; 2(25):1-10.
15. Pashley EL., Zhang Y., Lockwood PE., Rueggeberg FA., Pashley DH: Effects of HEMA on water evaporation from water-HEMA mixtures. Dent Mater. 1998; 14:6-10.

16. Giannini M., Arrais CA., Vermelho PM., Reis RS., dos Santos LP., Leite ER: Effects of the solvent evaporation technique on the degree of conversion of one-bottle adhesive systems. Oper Dent. 2008; 33:149-154.

17. Yiu CKY., Pashley EL., Hiraishi N., King NM., Goracci C., Ferrari M., Carvalho RM., Pashley DH, Tay FR: Solvent and water retention in dental adhesive blends after evaporation. Biomater.2005; 26:6863-6872.

18. Yoshihara K., Nagaoka N., Okihara T., Kuroboshi M., Hayakawa S., Maruo Y.: Functional monomer impurity affects adhesive performance. Dent Mater. 2015; 31:1493501.

19. Iwai H., Nishiyama N.: Effect of calcium salt of functional monomer on bonding performance. J Dent Res.2012; 91:1043-8.

20. Chen C, Niu LN, Xie H, Zhang ZY, Zhou LQ, Jiao K.: Bonding of universal adhesives to dentine-old wine in newbottles? J Dent .2015;43:525-36.

21. Perdigao J., Sezinando A., Monteiro PC. Effect of substrate age and adhesive composition on dentin bonding. Oper Dent. 2013; 38:267-274.

22. Thanatvarakorn O., Prasansuttiporn T., Takahashi M., Thittaweerat S., Foxton RM., Ichinose S., Tagami J., Nakajima M.: Effect of scrubbing technique with mild self-etching adhesives on dentin bond strengths and nanoleakage expression. J Adhes Dent. 2016; 18:197-204. 